02

\title{
Поверхностные поляритоны в пленках нитридов алюминия и галлия, легированных кремнием
}

\author{
(C) Н.Н. Новикова ${ }^{1}$, В.А. Яковлев ${ }^{1}$, С.А. Климин ${ }^{1, \uparrow, ~ Т . В . ~ М а л и н ~}{ }^{2}$, А.М. Гилинский ${ }^{2}$, К.С. Журавлев ${ }^{2,3}$ \\ ${ }^{1}$ Институт спектроскопии РАН, \\ 108840 Москва, Троицк, Россия \\ ${ }^{2}$ Институт фризики полупроводников им. А.В. Ржанова Сибирского отделения РАН, \\ 630090 Новосибирск, Россия \\ ${ }^{3}$ Новосибирский государственный университет, \\ 630090 Новосибирск, Россия \\ ฯ e-mail:klimin@isan.troitsk.ru
}

Поступила в редакцию 25.02.2018 г.

В окончательной редакции 25.02.2018 г.

Принята к публикации 15.03.2019 г.

\begin{abstract}
Измерены спектры отражения и спектры нарушенного полного внутреннего отражения сильно легированных кремнием пленок нитридов алюминия и галлия на сапфировых подложках с буферным слоем нитрида алюминия. В спектрах нарушенного полного внутреннего отражения наблюдались поверхностные фононные и плазмон-фононные поляритоны. Экспериментально наблюдалась высокая концентрация носителей в пленке нитрида галлия и их практическое отсутствие в пленке нитрида алюминия.
\end{abstract}

Ключевые слова: нитриды алюминия и галлия, спектры отражения, поверхностные поляритоны

DOI: $10.21883 /$ OS.2019.07.47929.84-19

\section{Введение}

Нитриды галлия, алюминия, индия и твердые растворы на их основе (Аз-нитриды) являются прямозонными широкозонными перспективными материалами для оптоэлектронных устройств. А рокое применение в фотодетекторах, светоизлучающих приборах, в полевых транзисторах, работающих под большим напряжением и при высоких температурах. Открытие широкополосной сверхлюминесценции в диапазоне $1.72-2.7 \mathrm{eV}$ при возбуждении низкоэнергетическими электронными пучками, обусловленной оптическими переходами через уровни дефектов в сильно легированных донорами слоях А $_{3}$-нитридов [1], возобновило к ним интерес как к перспективным источникам света, перестраиваемым в широком диапазоне длин волн, стимулируя всестороннее исследование этих твердых растворов. Так, в работе [2] при оптической накачке импульсным лазерным излучением с $\lambda=266 \mathrm{~nm}$ твердых растворов А 3 -нитридов, синтезированных методом молекулярнолучевой эпитаксии, были исследованы спектральные характеристики спонтанной и стимулированной люминесценции и измерены коэффициенты усиления в них. В работе [3] проведено исследование методами рентгеновской дифрактометрии деформационных состояний и дефектной структуры эпитаксиальных слоев $\mathrm{A}_{3}$-нитридов состава $\mathrm{Al}_{x} \mathrm{Ga}_{1-x} \mathrm{~N}$, легированных кремнием. Найдено, что для $x<0.4$ латеральные остаточные напряжения имеют компрессионный характер, в то время как для $x>0.4$ они становятся растягивающими.

Настоящая работа посвящена исследованию сильно легированных кремнием слоев $\mathrm{AlN}$ и GaN методами ИК спектроскопии отражения и поверхностных поляритонов, что позволило обнаружить существенное отличие в концентрации свободных носителей заряда в исследуемых образцах.

\section{Методы эксперимента}

\section{Эпитаксиальный рост образцов}

Эпитаксиальные слои структур $\mathrm{AlN}$ и $\mathrm{GaN}$ толщиной $\sim 1 \mu \mathrm{m}$ выращивались методом молекулярно-лучевой эпитаксии на установке RIBER-32 с применением аммиака в качестве источника активного азота на подложках (0001) сапфира. В качестве буферного слоя на подложках сапфира формировался слой AlN толщиной $\sim 300 \mathrm{~nm}$. Температура роста слоев в зависимости от состава варьировала в диапазоне от $780^{\circ} \mathrm{C}$ (для слоя бинарного $\mathrm{GaN}$ ) до $940^{\circ} \mathrm{C}$ (для бинарного $\mathrm{AlN}$ ). Задаваемый при росте слоев поток аммиака также изменялся от 10 (AlN) до $200 \mathrm{sccm}(\mathrm{GaN})$. Обе структуры легировались кремнием, источником которого был силан. Для легирования образцов использовался фиксированный поток силана, $f=0.021 \mathrm{sccm}$. Электрофизические свойства исследуемых слоев определялись посредством измерений эффекта Холла.

\section{Спектры отражения и нарушенного полного внутреннего отражения}

Спектры отражения при комнатной температуpe были измерены при помощи фурье-спектрометра BRUKER IFS66 v/s в спектральном интервале от 30 до 
$4500 \mathrm{~cm}^{-1}$ при падении излучения, близком к нормальному. Спектральное разрешение составляло $4 \mathrm{~cm}^{-1}$. Из них с помощью дисперсионного анализа (ДА) были получены параметры оптических фононов. Для этого экспериментальные спектры сравнивались с расчетом, использующим формулы Френеля для отражения от многослойной структуры. Минимизация разницы этих спектров программой SCOUT [4] позволяет получить параметры слоев (толщины, а также частоты и затухание оптических фононов и плазмонов). При этом диэлектрическая проницаемость пленок предполагалась в виде

$$
\varepsilon(\nu)=\varepsilon_{\infty}-\frac{\varepsilon_{\infty} v_{\mathrm{p}}^{2}}{v^{2}+i \nu \nu_{\tau}}+\frac{S^{2}}{v_{\mathrm{TO}}^{2}-v^{2}-i \nu \gamma} .
$$

Здесь $\varepsilon_{\infty}$ - высокочастотная диэлектрическая проницаемость, $v_{\text {то }}$ - частота поперечного (ТО) фонона, $S$ - его сила осциллятора, $\gamma-$ его затухание, $v_{\mathrm{p}}-$ плазменная частота, $v_{\tau}$ - частота соударений свободных носителей.

При измерении спектров нарушенного полного внутреннего отражения (НПВО) в указанных структурах могут наблюдаться поверхностные поляритоны (ПП) [5]. ПП являются нерадиационными (волновой вектор больше волнового вектора света в вакууме, $\left.k_{x}>\omega / c\right)$ электромагнитными возбуждениями, распространяющимися вдоль границ раздела. Они существуют на границе двух сред, если диэлектрические проницаемости контактирующих веществ имеют разные знаки [5-8], при этом поле ПП экспоненциально убывает при удалении от слоистой структуры и в подложку, и в вакуум. Отрицательная Reع может быть либо ниже плазменной частоты при наличии в структуре свободных носителей (плазмонный ПП), либо между частотами поперечного (ТО) и продольного (LO) фононов (фононный ПП). Следует заметить, что ПП чувствует все слои и является возбуждением всей структуры, а не отдельного ее слоя или границы.

Спектры ПП (спектры НПВО) в средней ИК области $\left(300-4000 \mathrm{~cm}^{-1}\right)$ с разрешением $4 \mathrm{~cm}^{-1}$ в $p$-поляризованном свете измерялись в геометрии Отто [9] с призмой KRS-5 при изменении угла падения света в призме от $20^{\circ}$ до $45^{\circ}$. Вакуумный зазор между призмой и образцом регулировался сменой лавсановых прокладок микронной толщины. Расчет спектров ПП выполнялся при помощи программы SCOUT [4].

\section{Результаты исследований}

Спектры отражения для пленок $\mathrm{AlN}: \mathrm{Si}$ и $\mathrm{GaN}: \mathrm{Si}$ сильно отличаются друг от друга (рис. 1). Для пленки $\mathrm{GaN}$ : Si на фоне высокого отражения ниже $2000 \mathrm{~cm}^{-1}$ совсем нет полос, относящихся к подложке сапфира, которые хорошо видны для пленки $\mathrm{AlN}$ :Si. Такое отличие связано с большой разницей в проводимости пленок. Исследования эффекта Холла показали, что слой $\mathrm{AlN}$ : Si является практически диэлектриком, в то время как для $\mathrm{GaN}: \mathrm{Si}$ концентрация электронов составляет

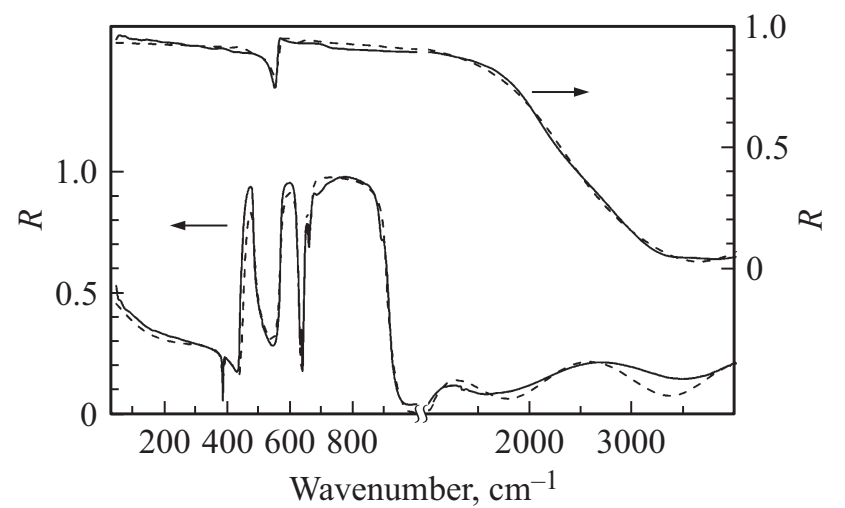

Рис. 1. Экспериментальные (сплошные линии) и расчетные (штриховые) ИК спектры отражения для пленок $\mathrm{GaN}: \mathrm{Si}$ (вверху) и $\mathrm{AlN}: \mathrm{Si}$ (внизу).

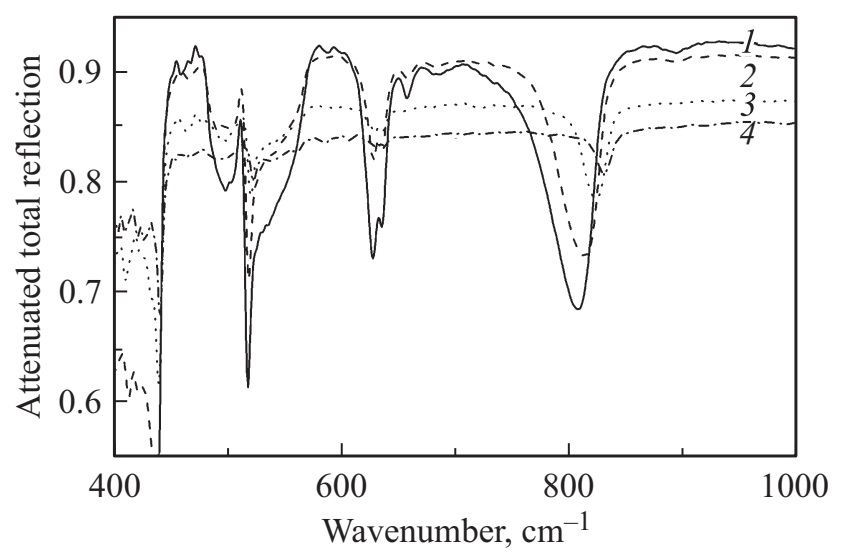

Рис. 2. Экспериментальные спектры НПВО для образца $\mathrm{AlN}: \mathrm{Si}$ при 4 углах падения в призме: $1-30^{\circ}, 2-32^{\circ}$, $3-36^{\circ}, 4-40^{\circ}$.

$n=1.1 \cdot 10^{20} \mathrm{~cm}^{-3}$. Это обусловливает металлический ход кривой отражения галлиевого образца, связанный с возбуждением плазмонных мод в слое.

Экспериментальные спектры отражения (рис. 1) сравнивались с расчетом. Подгонка расчетных спектров к экспериментальным позволила получить параметры слоев (см. таблицу). Обращает внимание большая величина плазменной частоты $v_{\mathrm{p}}=\omega_{\mathrm{p}} / 2 \pi c(c-$ скорость света в вакууме) для слоя $\mathrm{GaN}: \mathrm{Si}$. Оценка плазменной частоты в рамках модели свободных электронов по формуле

$$
\omega_{\mathrm{p}}=\sqrt{\frac{n e^{2}}{m \varepsilon_{0}}}
$$

где $n$ - концентрация носителей, $e-$ заряд электрона, $m$ - масса электрона, $\varepsilon_{0}$ - электрическая постоянная, дает $v_{\mathrm{p}} \approx 3200 \mathrm{~cm}^{-1}$, близкое к значению плазменной частоты, приведенному в таблице.

Анализ параметров показал, что, действительно, в исследуемых структурах выполняются условия для наблюдения ПП. Спектры НПВО представлены на рис. 2-4. 
Параметры пленок и буферных слоев исследуемых структур. Для сапфира использовались параметры, приведенные в [10]

\begin{tabular}{c|c|c|c|c|c|c|c|c}
\hline Structure & Layer & Thickness, $\mathrm{nm}$ & $\varepsilon_{\infty}$ & $v_{\mathrm{p}}, \mathrm{cm}^{-1}$ & $v_{\tau} \mathrm{cm}^{-1}$ & $\nu_{\mathrm{TO}}, \mathrm{cm}^{-1}$ & $S, \mathrm{~cm}^{-1}$ & $\gamma, \mathrm{cm}^{-1}$ \\
\hline \multirow{2}{*}{$\mathrm{AlN}: \mathrm{Si}$} & film & 1120 & 4.83 & 220 & 69 & 668 & 1350 & 5 \\
& buffer & 260 & 4.97 & 117 & 120 & 688 & 1510 & 20 \\
\hline \multirow{2}{*}{$\mathrm{GaN}: \mathrm{Si}$} & film & 412 & 7.89 & 2600 & 280 & 566 & 1620 & 11 \\
& buffer & 216 & 5.66 & 440 & 130 & 651 & 2060 & 28
\end{tabular}

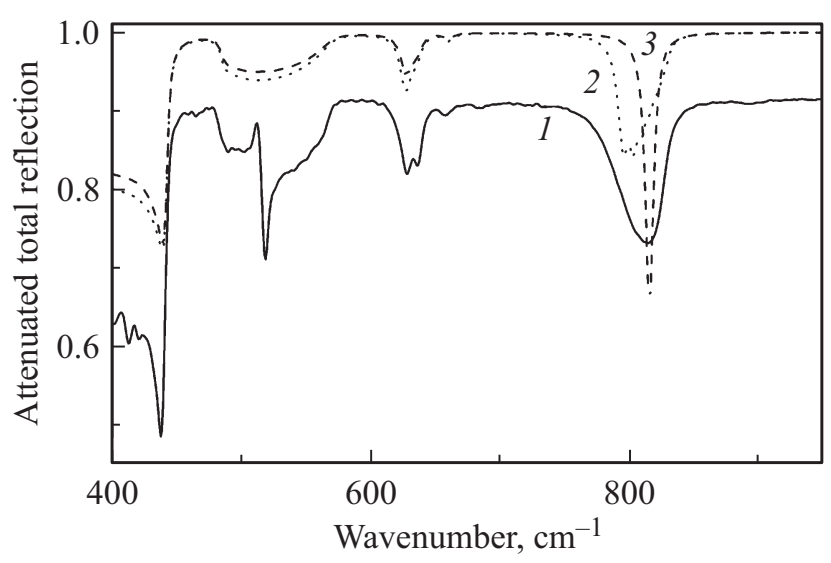

Рис. 3. Сравнение экспериментального и рассчитанных спектров НПВО для образца $\mathrm{AlN}: \mathrm{Si}$ при угле падения в призме $30^{\circ}: 1$ - эксперимент, 2 - расчет с угловой расходимостью $4^{\circ}, 3-$ расчет с параметрами таблицы (параллельный пучок).

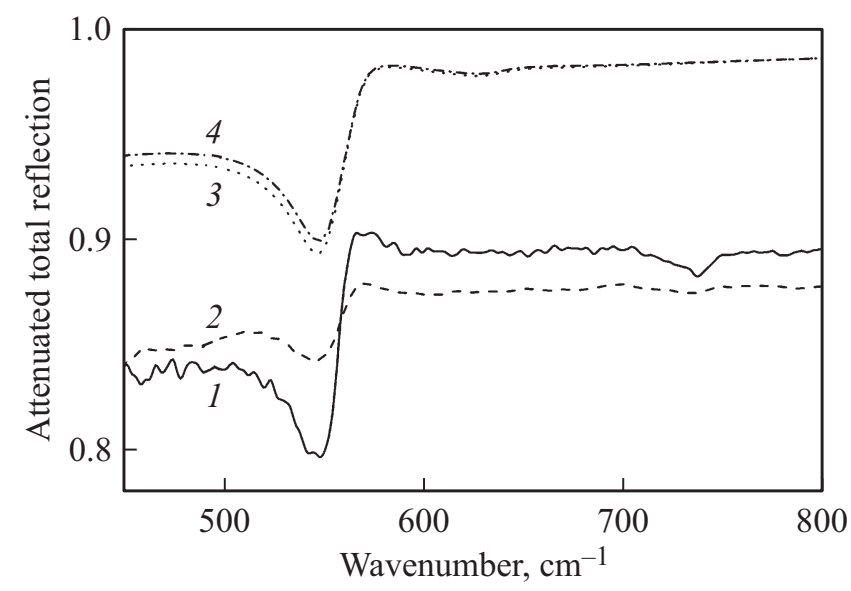

Рис. 4. Экспериментальные спектры НПВО для образца GaN в сравнении с рассчитанными: при двух углах падения в призме: 1 - эксперимент $30^{\circ}, 2-$ эксперимент $34^{\circ}$; 3 расчет при угле падения в призме $30^{\circ}$, зазор $5 \mu \mathrm{m} ; 4-$ расчет при угле падения в призме $34^{\circ}$, зазор $3 \mu \mathrm{m}$.

Они также существенно различаются для двух исследуемых образцов. Для слоя $\mathrm{AlN}: \mathrm{Si}$ поверхностная волна проникает глубоко внутрь и хорошо чувствует сапфировую подложку. В спектре в этом случае наблюдается значительное число пиков (фононного типа), обусловленных граничными условиями для трех сред: воздуха, нитрида алюминия и сапфира. В случае $\mathrm{GaN}: \mathrm{Si}$ большая концентрация электронов приводит к быстрому затуханию поверхностной волны и экранизации глубоко лежащих возбуждений. В результате в спектре присутствует малое число полос.

На рис. 3 и 4 расчет по полученным в результате дисперсионного анализа параметрам сравнивается с экспериментом. Для $\mathrm{AlN}: \mathrm{Si}$ (рис. 3) рассчитанный ПП с частотой вблизи $830 \mathrm{~cm}^{-1}$ (кривая 3), намного уже измеренного (кривая 1). Это обусловлено угловой расходимостью ИК излучения в призме. Если предположить расходимость $\pm 2^{\circ}$, различие уменьшается (кривая 2). Другое отличие между измеренным и расчетным спектрами (полоса $520 \mathrm{~cm}^{-1}$ ), возможно, связано с появлением переходного слоя между пленкой и буфером. В спектре НПВО для образца $\mathrm{GaN}: \mathrm{Si}$ (рис. 4) есть один сильный пик $550 \mathrm{~cm}^{-1}$, который можно отнести к плазмон-фононному ПП. Второй широкий пик (преимущественно плазмонный) наблюдается между 1000 и $2000 \mathrm{~cm}^{-1}$.

Для построения кривых дисперсии ПП мы определяли положения минимумов в спектрах НПВО структур (призма-вакуумный зазор-пленка-буферный слойсапфир) с полученными из ДА параметрами при разных углах падения в призме. Углы от $25^{\circ}$ до $60^{\circ}$ соответствуют приведенным волновым векторам ПП $\kappa_{x}=k_{x} c / \omega$ от 1 до 2 , где $\kappa_{x}=1$ (световая прямая) соответствует свету, распространяющемуся вдоль поверхности и над ней. Зазоры выбирались достаточно большими для минимизации влияния призмы на положение минимума.

Рассчитанные кривые дисперсии ПП обоих образцов в сравнении с экспериментальными данными представлены на рис. 5 и 6. Вертикальные линии справа показывают области отрицательной $\operatorname{Re} \varepsilon$ для каждой из трех сред. Для структуры с пленкой $\mathrm{AlN}: \mathrm{Si}$ в спектральной области выше $1000 \mathrm{~cm}^{-1}$ действительная часть диэлектрической проницаемости положительна у всех сред, поэтому верхняя кривая рис. 5 не связана с ПП, а обусловлена интерференцией в пленках. Остальные ПП - фононные, так как плазменные частоты всех сред ниже $400 \mathrm{~cm}^{-1}$ (таблица).

У пленки GaN : Si Rec < 0, и верхнюю кривую рис. 6 можно отнести к плазмонному ПП. Остальные ПП . преимущественно фононные, модифицированные плазмоном пленки GaN. Рассчитанные кривые дисперсии ПП в основном согласуются с экспериментом (за исключением полосы $520 \mathrm{~cm}^{-1}$ для пленки $\mathrm{AlN}: \mathrm{Si}$ и очень слабой полосы $740 \mathrm{~cm}^{-1}$ для пленки $\left.\mathrm{GaN}: \mathrm{Si}\right)$. 


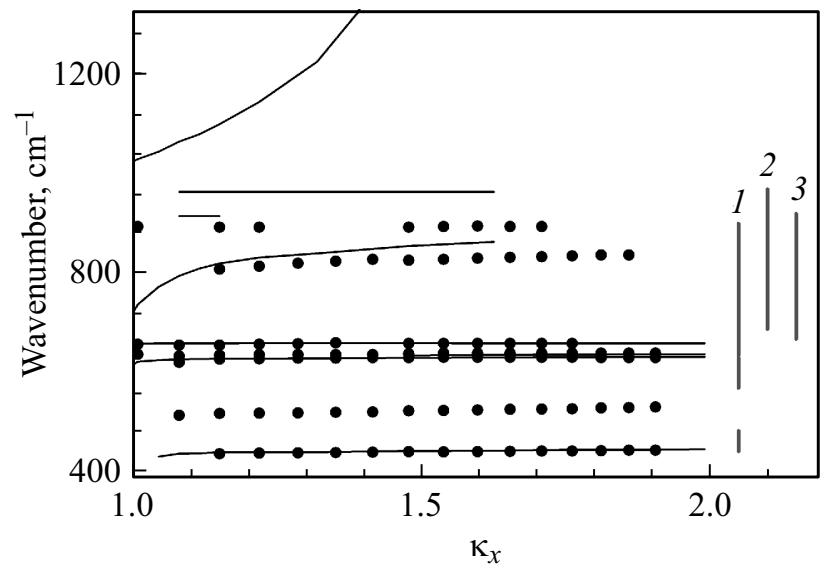

Рис. 5. Расчетные кривые дисперсии ПП для образца $\mathrm{AlN}: \mathrm{Si}$ (сплошные линии) и экспериментальные данные (точки). Серые вертикальные линии показывают область отрицательной $\operatorname{Re} \varepsilon$ для сапфировой подложки (1), буферного слоя (2) и пленки $\mathrm{AlN}: \mathrm{Si}(3)$.

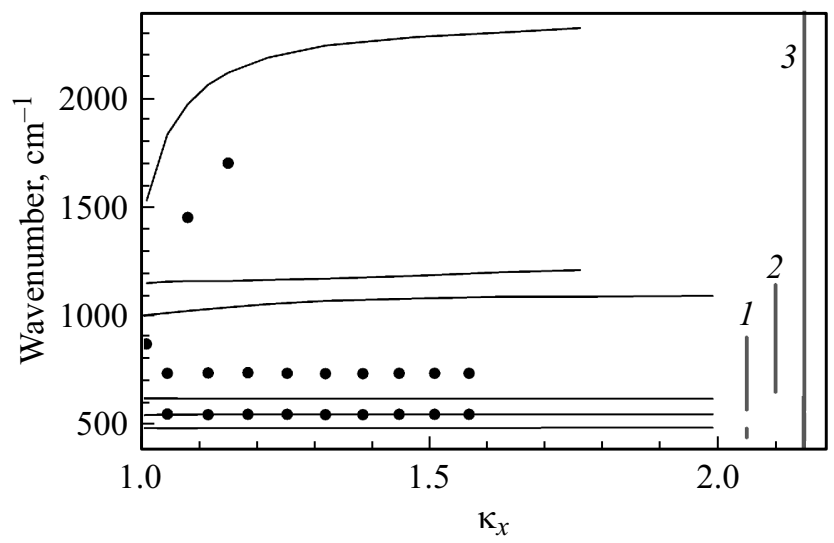

Рис. 6. Расчетные кривые дисперсии ПП для образца $\mathrm{GaN}: \mathrm{Si}$ (сплошные линии) и экспериментальные данные (точки). Серые вертикальные линии показывают область отрицательной $\operatorname{Re} \varepsilon$ для сапфировой подложки (1), буферного слоя (2) и пленки $\mathrm{GaN}: \mathrm{Si}(3)$.

\section{Выводы}

Таким образом, в настоящей работе исследованы спектры отражения и НПВО легированных кремнием структур AlN и GaN на сапфировых подложках с буферным слоем AlN. Толщины и параметры фононов и плазмонов пленок получены из дисперсионного анализа спектров отражения. В спектрах НПВО таких структур впервые экспериментально наблюдались поверхностные фононные и плазмон-фононные поляритоны. Рассчитаны кривые дисперсии ПП. Измеренные частоты ПП удовлетворительно согласуются с расчетными данными. Наблюдалась высокая концентрация электронов в пленке $\mathrm{GaN}: \mathrm{Si}$ и их практическое отсутствие в диэлектрике AlN : Si.

\section{Финансирование работы}

Работа поддержана Программой Президиума РАН I.7 „Современные проблемы фотоники, зондирования неоднородных сред и материалов“ (авторы ННН, САК, ВАЯ) и РФФИ, проект № 18-52-00008 (ТВМ, АМГ, КСЖ).

\section{Конфликт интересов}

Авторы заявляют, что у них нет конфликта интересов.

\section{Список литературы}

[1] Bokhan P.A., Gugin P.P., Zakrevsky Dm.E., Zhuravlev K.S., Malin T.V., Osinnykh I.V., Solomonov V.I., Spirina A.V. // J. Appl. Phys. 2014. V. 116. P. 113103.

[2] Бохан П.А., Журавлёв К.С., Закревский Дм.Э., Малин Т.В., Осинных И.В., Фатеев Н.В. // Письма в ЖТФ. 2017. Т. 43. № 1. C. 5.

[3] Ратников В.В., Щеглов М.П., Бер Б.Я., Казанщев Д.Ю., Осинных И.В., Малин Т.В., Журавлев К.С. // ФТП. 2018. T. 52. № 2. C. 233.

[4] Theib W. // Surface Sci. Rep. 1997. V. 29. P. 91.

[5] Surface Polaritons. Electromagnetic Waves at Surfaces and Interfaces / Ed. by Agranovich V.M. Mills D.L. Amsterdam: North-Holland Publ. Co., 1982. 717 p.

[6] Agranovich V.M., Malshukov A.G. // Opt. Commun. 1974. V. 11. P. 169.

[7] Виноградов Е.А., Дорофеев И.А. // УФН. 2009. Т. 179. № 5. C. 449.

[8] Dorofeyev I.A., Vinogradov E.A. // Phys. Rep. 2011. V. 504. P. 75.

[9] Otto A. // Zs. Phys. 1968. V. 216. P. 398.

[10] Barker A.S. // Phys. Rev. 1963. V. 132. P. 1474. 